\title{
Patolojik yürüme
}

\author{
Pathological gait \\ İlker Sarıkaya ${ }^{1}$, Muharrem İnan² \\ ${ }^{1}$ Çocuk Ortopedi Kliniği, İstanbul \\ ${ }^{2}$ istanbul Üniversitesi Cerahpaşa Tıp Fakültesi, Ortopedi ve Travmatoloji Anabilim Dalı, İstanbul
}

\begin{abstract}
Patolojik yürüme vücudun tekrarlayan doğal hareketler vasıtası ile öne taşınma işleminde meydana gelen aksaklıklar olarak kabul edilmektedir. Yürüme döngüsünü olumsuz yönde etkileyen patolojik etmenler; ağrı, deformite, azalmış duyusal ya da motor kontrol, denge olarak sıralanır. Patolojik yürüyüş düzeni, ayak bileği eklemi üzerinde aşırı plantar fleksiyon ya da dorsifleksiyon oluşturur; diz eklemini sagittal düzlemde etkileyerek aşırı fleksiyon veya ekstansiyona neden olur. Yürüyüş anormallikleri, kalça eklemi üzerinde fleksiyon, ekstansiyon, adduksiyon, abduksiyon, ve rotasyonel deformasyonlara yol açar. Kuşkusuz bunların anlaşılması sorunların çözümünde birinci basamak olacaktır.
\end{abstract}

Anahtar sözcülkler: yürüyüş; üç boyutlu; yürüme deformitesi; spastisite

\section{Giriş̧}

Normal ve sağlıklı bir yürüme döngüsü, en az enerji ile vücudun öne doğru ilerletilmesini sağlayacak iskelet-kas gücüne, ayak yer ile temas ettiğinde vücut ağırlığının neden olduğu darbeyi algılayacak propriyosepsiyon duyusuna, şok emilimi yeteneğine ve tüm bu etmenler arasında koordinasyona ihtiyaç duyar. ${ }^{[1-3]}$ Patolojik yürüme ise vücudun tekrarlayan doğal hareketler vasıtası ile öne taşınma işleminde meydana gelen aksaklıklar olarak kabul edilmektedir. Birçok patolojinin yürüme döngüsünü olumsuz yönde etkilediği bilinmektedir; ${ }^{[4,5]}$ işte bu patolojik etmenlerin yürüme döngüsü üzerine yansımaları beş başlıkta sınıflanabilir:

1. Ağrı

2. Deformite

3. Kas güçsüzlüğü

4. Azalmış motor ya da duyusal kontrol

5. Denge
Pathological gait can be defined as a disturbance, which occurs when the body moves forward through repetitive natural motions. The pathological factors, which affect the gait cycle are pain, deformity, decreased sensorial or motor control and balance. Pathological gait pattern on the ankle joint cause excessive plantar flexion or dorsiflexion, and on the knee joint affect the sagittal plane and cause excessive flexion or extension. Gait abnormalities on the hip joint cause flexion, extension, adduction, abduction, and rotational deformities. Diagnosis of these abnormalities is the first step to proper treatment.

Key words: gait; three-dimensional; gait deformity; spasticity

\section{AĞRI}

Ağrı genellikle yürüme döngüsünde hızın azalmasına, ağrılı ekstremitede basma aşamasının kısa sürmesi ile kendini gösteren antaljik yürüme biçimine neden olur. Öncelikle eklem içi basınç artışının ortaya çıkardığı ağrı, yürüme döngüsünü deformiteye ve kas güçsüzlüğüne neden olarak etkiler. ${ }^{[6]}$

\section{DEFORMITE}

Deformite, yürüme döngüsü esnasında gerekli eklem hareket açıklığının sağlanamamasına ve vücut postürünün bozulmasına neden olan aksaklık olarak kabul edilir. Patolojik yürümeye yol açan deformiteler arasında eklem kontraktürleri ilk sırayı alır. Eklem kontraktürleri elastik ve sert olarak sınıflandırılır. ${ }^{[7,8]}$ Eklemin manipülasyon ile düzeltilebilmesi elastik-sert kontraktür ayrımında yol göstericidir. Elastik eklem kontraktürleri artmış kas spastisitesine ya da bağ laksitesine ikincil olarak gelişir. Elastik eklem kontraktürü varlığı zaman zaman yürüme döngüsünün basma aşamasının

- İletişim adresi: Dr. İlker Sarıkaya, Hakkı Yeten Caddesi Unimed Centre Kat: 8 Fulya, Şişli, İstanbul Tel: 0212 - 2969450 e-posta: drsarikayailker@gmail.com

- Gelis tarihi: 23 Temmuz 2014 Kabul tarihi: 23 Temmuz 2014 
normal ya da normale yakın değerlendirilmesine neden olsa da salınım aşamasında vücut ağırlığının düzeltici etkisinin ortadan kalkması nedeniyle daima kaydedilir olmaktadır. Sert eklem kontraktürleri ise yürüme döngüsünde daima gözlemlenebilir ve ölçülebilir patolojilere yol açar.

\section{KAS GÜÇSÜZLÜĞÜ}

Yürüme fonksiyonu için kas dengesi ve gücü önemlidir. Bu noktada kas gücünü değerlendiren klinik testler hastanın yürüme potansiyeli hakkında yetersiz kalır ve sayısal analiz gerekliliği ortaya çıkar. ${ }^{\left[{ }^{[-11]}\right.}$ Kas güçsüzlüğü ile karşılaşılan durumlarda birçok adaptasyon mekanizması devreye girer. Öncelikle artmış motor kontrol vasıtası ile enerji tasarrufu sağlanır ve normale yakın yürüme biçimine ulaşılır. Daha sonra ise yürüme hızı azalır ve vücut öncelikle yürüme döngüsünün basma aşamasında ortaya çıkan koruyucu postürü alır.

\section{AZALMIŞ MOTOR VE DUYUSAL KONTROL}

\section{Azalmış motor kontrol}

Santral sinir sistemini hasara uğratan durumlarda iskelet kas sistemi üzerindeki seçici kontrol mekanizmaları yetersiz kalır ve genellikle "spastisite" olarak tanımlanan durum ortaya çıkar. ${ }^{[12]}$ Spastik yürümenin en sık görülen nedenleri, serebral palsi, inme ve spinal kord yaralanmaları olarak sayılabilir. ${ }^{[13]}$ Motor kontrol zafiyetinin kliniğe yansıması her hastada farklı düzeyde olabilir. Ani gerilme esnasında klonus ile ortaya çıkan spastisite, yavaş gerilme esnasında devamlı kas aktivitesi ile kendini gösterir.

\section{Azalmış duyusal kontrol}

Duyusal kontrol, vücut postürünün sürdürülebilmesi ve yürüme döngüsü için gereklidir. ${ }^{[14]}$ Motor kontrolün zarar görmediği durumlarda bile, propiyosepsiyon duyusunun zarar görmesi yürüme fonksiyonunu aksatır; yürüme hızı azalır, duraksama meydana gelir, ilerleyen durumlarda ise yürüme döngüsü sürdürülemez bir hal alır. Duyusal kontrol, yok, hasarlı ve sağlam olarak sınıflandırılır.

\section{DENGE}

Denge (balans) mekanizmaları yürüme döngüsü için gereklidir ve merkezi sinir sistemi tarafından kontrol edilir. ${ }^{[15]}$ Örneğin, yürüme yetisine sahip fakat durma güçlüğü taşıyan bir kişi kısa adımlar kullanır ya da kollarını uzatarak denge sağlamaya çalışır. Yaşamın ilk üç yılında hızlı bir şekilde gelişen denge mekanizmaları sekiz yaşına kadar gelişimini tamamlamakta ve erişkin tip yürüme biçiminin kazanılmasına katkı sağlamaktadır. Denge sorunu yaşanan durumlarda genellikle adım uzunluğu ve kadansta farklılıklar tespit edilir.

\section{PATOLOJIK YÜRÜME}

Patolojik yürüme tek eklemdeki probleme bağlı olabileceği gibi birçok eklemi ilgilendiren karmaşık durumlar olarak da ortaya çıkar. Tedaviyi uygulayacak hekim adaptasyon mekanizmaları konusunda dikkatli olmalı ve temel patolojiyi ortaya çıkaracak klinik testleri uygulamalıdır. Biz konunun anlaşılmasını kolaylaştırmak amacıyla eklem patolojilerini tek tek ele aldık.

\section{Ayak bileği patolojilerine bağlı patolojik yürüme}

Ayak bileği, yük aktarımı esnasında şok emici rol üstlenir ve öne doğru hareket için enerji kaynağı olarak görev yapar. ${ }^{[16]}$ Ayak bileği kaynaklı yürüme bozuklukları plantar fleksiyonda artmaya neden olan patolojiler (parmak ucu yürüyüş) ve dorsifleksiyonda artmaya neden olan patolojiler (topuk yürüyüşü) olarak sınıflanabilir.

\section{Ekin "parmak ucu” yürüyüşü}

Yürüme döngüsü esnasında ayak bileği plantar fleksiyonunda artış vardır. Aşil kontraktürü, dorsifleksiyon yaptıran kasların yetersizliği, ekstremite kısalığı ya da diz-kalça fleksiyon kontraktürü sonrasında telafi edici olarak parmak ucu yürüyüşü görülür (Şekil 1).

Sağlıklı bir yürüme döngüsünün topuk teması aşamasında ayak bileği nötral pozisyonda ve ayak supinasyonda olmalıdır. Bu aşamada artmış plantar fleksiyon, azalmış topuk temasına ya da temasın ön ayak ile sağlanmasına neden olur. Artmış ayak bileği plantar fleksiyonuna eşlik eden artmış diz fleksiyonu durumunda topuk teması sağlanamaz ve ön ayak teması meydana gelir.

Ön ayak dokunuşu ile seyreden ilk temas durumunda yüklenmenin karşılanması aşamasında, ayak bileğinin esnekliğine göre farklı senaryolar karşımıza çıkar. Illk senaryoda, ayak bileği yeterli derecede esnek ise hızlı topuk teması gerçekleşir. Ikinci senaryoda, ayak bileği yeterli derecede esnek değil ise, ya diz geri kaçar ve topuk teması sağlanır ya da topuk teması sağlanamadan yürüme döngüsü devam eder (Şekil 2). Artmış kalça ve diz fleksiyonu bu patolojik durumun sonuçlarını gidermek için devreye giren mekanizmalardır.

Parmak ucu yürüyüş sırasında tibianın öne doğru ilerlemesi azalır, "ayak bileği dönmesi" (ankle rocker) bozulur. Bu aşamada üç farklı mekanizma ile gövdenin öne ilerletilmesi sağlanmaya çalışılır ve yürüme döngüsü sürdürülür. 


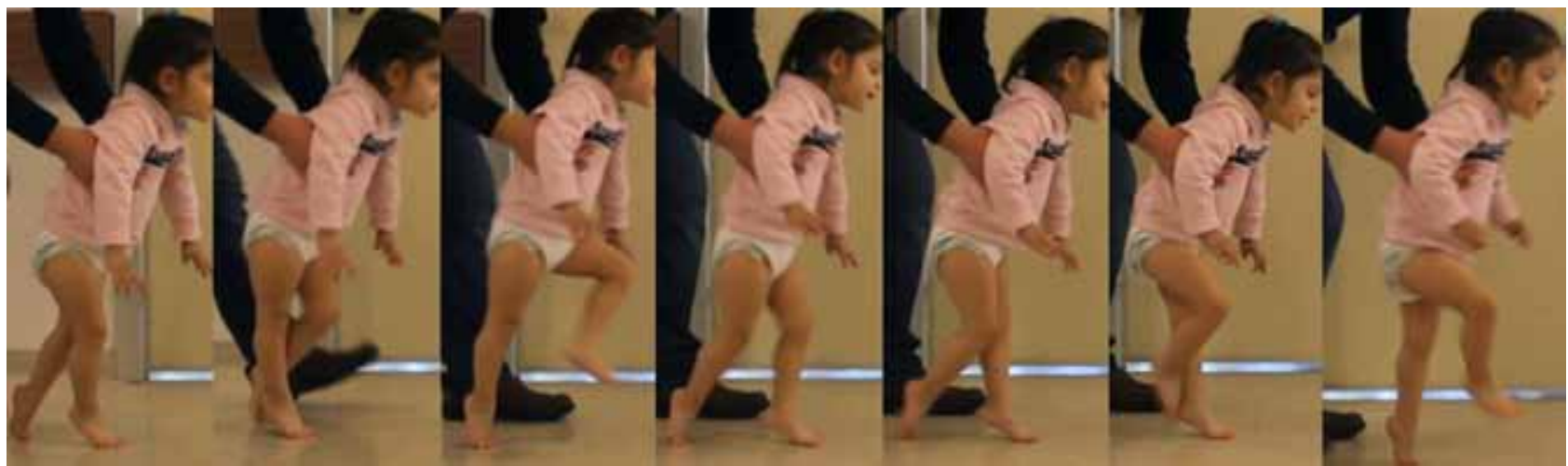

Şekil 1. Görsel yürüme analizi ile parmak ucu yürüyüşünün incelenmesi; yürüme döngüsünün hiçbir fazında topuk temasının sağlanamamakta olduğu görülüyor.

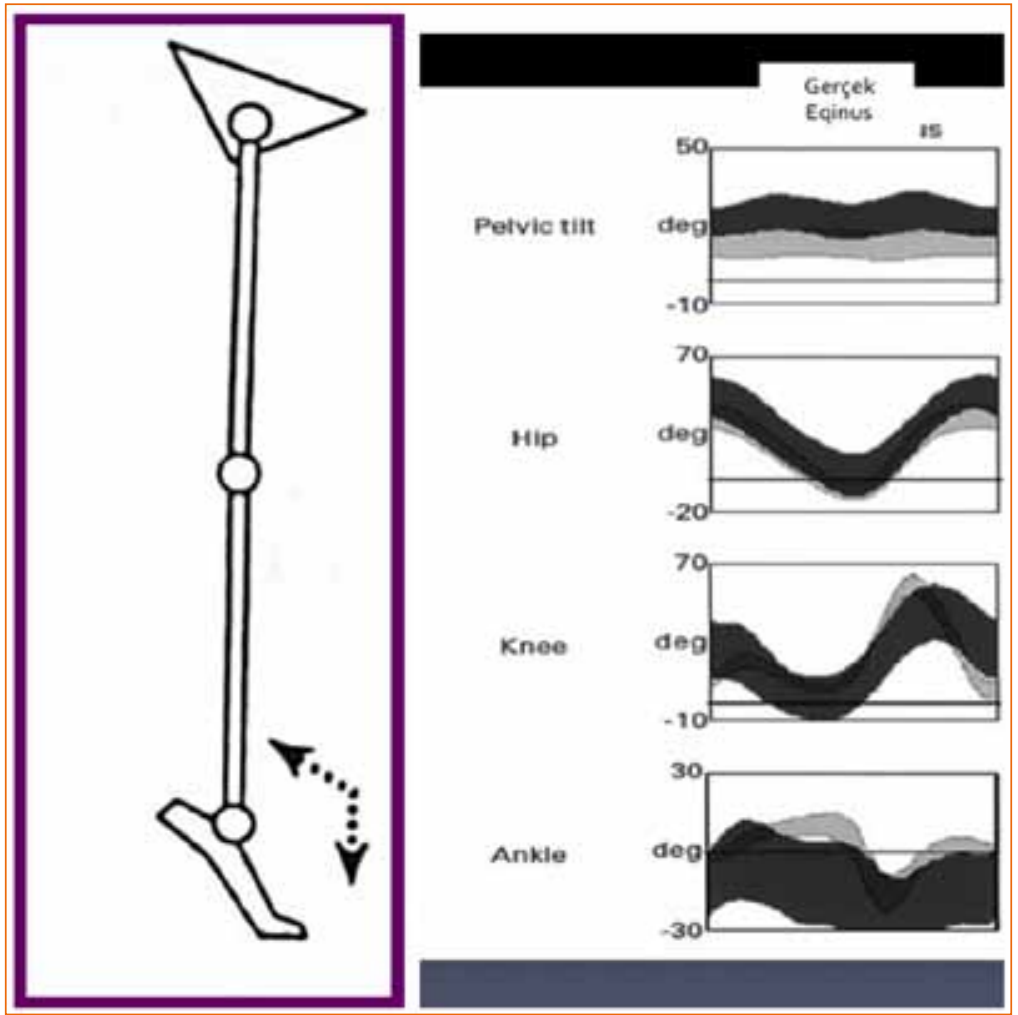

Şekil 2. Şematik çizimde ve yürüme analizi incelemesinde ayak bileğinde plantar fleksiyonun arttığı fakat diz ve kalça eklemlerinde ekstansiyonun sağlanabildiği gerçek ekin deformitesi görülüyor.

1. Erken topuk kalkışı: Erken topuk kalkışı gerçekleşmesi durumunda basma aşamasının süresi kısalır ve yürüme hızı düşer.

2. Diz hiperekstansiyonu: Bağ laksitesinin arttığı durumlarda femur ve gövde tibia üzerinden öne doğru hareket eder. Bu durum sıklıkla serebral palside ve medulla spinalis yaralanmalarından sonra görülür.

3. Anterior pelvik tilt: Anterior pelvik tilt ile gövdenin öne doğru hareket etmesi sağlanır.

\section{Topuk yürüyüş}

Ayak bileği artmış dorsifleksiyonu, ayak bileğinde yürüme döngüsünün gerektirdiği hallerde plantar fleksiyonun gerçekleştirilememesi olarak da tanımlanabilir. Gastrosoleus kas grubunun güçsüzlüğü, ayak bileğinin cihaz ile ya da cerrahi sonrasında nötral pozisyonda stabil olamaması topuk yürüyüşüne neden olabilir. Bu durumlarda yüklenmenin karşılanması, salınım öncesi ve erken salınım aşamalarında bulgu veren ayak bileği 
artmış dorsifleksiyonu gözlemlenir (Şekil 3). ${ }^{[17]}$ Ayak bileği dorsifleksiyonda durduğu sürece topuk kalkışı bozulur, diz fleksiyona zorlanır, kuadriseps mekanizmasına normalden fazla yük biner, diğer ekstremitede adım uzunluğu kısalır.

Ayak bileği artmış dorsifleksiyonu sonucu yürümenin basma sonu aşamasında tibia öne doğru hareket ederken topuk kalkışı gerçekleşemez ya da topuk kalkışı gerçekleşse bile diz fleksiyona zorlanır. Tek ekstremite desteğinin başladığı bu aşamada stabilite bozulur, gövde ve tibia öne doğru hareket eder, diz ekstansiyonunda güçlük yaşanır.

\section{Diz patolojilerinin yürüme döngüsüne etkileri}

Dizin temel görevi basma aşamasında alt ekstremitenin uzunluğunu ayarlayarak stabiliteye katkı sağlamaktır. ${ }^{[18]}$ Diz eklemi yoluyla yürüme döngüsünü etkileyen patolojiler çoğunlukla sagittal planda gerçekleşen diz bükük yürüyüş, sıçrayarak yürüme ve sert diz yürüyüşüdür.

\section{Diz bükük yürüyüş}

Diz fleksiyonunda artma ya da diz ekstansiyonunda yetersizlik diz bükük yürüyüşüne neden olur. Hamstring artmış spastisitesi ya da kontraktürü, gastrosoleus aşırı aktivitesi, kuadriseps yetersizliği altta yatan başlıca patolojiler olarak sayılabilir. Orta dereceli diz fleksiyon deformitelerinde tek bulgu basma aşamasında tam ekstansiyonun gerçekleşememesidir ve bu patolojinin tespit edilmesi güçtür. Oysa daha ciddi deformitelerde basma ortası aşamasında diz ekstansiyon yetersizliği belirgin bir hal alır (Şekil 4). Bu durum kuadriseps mekanizmasının aşırı çalışmasına neden olur ve artmış kalça fleksiyonu ve ayak bileği dorsifleksiyonu meydana gelir. Diz bükük yürüyüş sonucunda enerji gereksinimi artar. ${ }^{[19]}$

Normalde basma ortası aşamasında diz ekstansiyona gelmeli ve basma sonu aşamasında fleksiyon görülmelidir. Oysa artmış diz fleksiyonu durumunda gövde öne doğru eğilir, kalça ekstansörleri gövdeyi dik tutmak için aşırı biçimde çalışır, adım mesafesi kısalır ve gövdenin öne doğru ilerlemesi güçleşir (Şekil 5).

\section{Sıçrayarak yürüme}

Sıçrayarak yürüme diplejik serebral palside sık görülen patolojik bir yürüme biçimidir. Klasik olarak yürümenin basma ortası aşamasında topuk temasının kısa olması ya da olmaması ile birlikte diz ve kalça

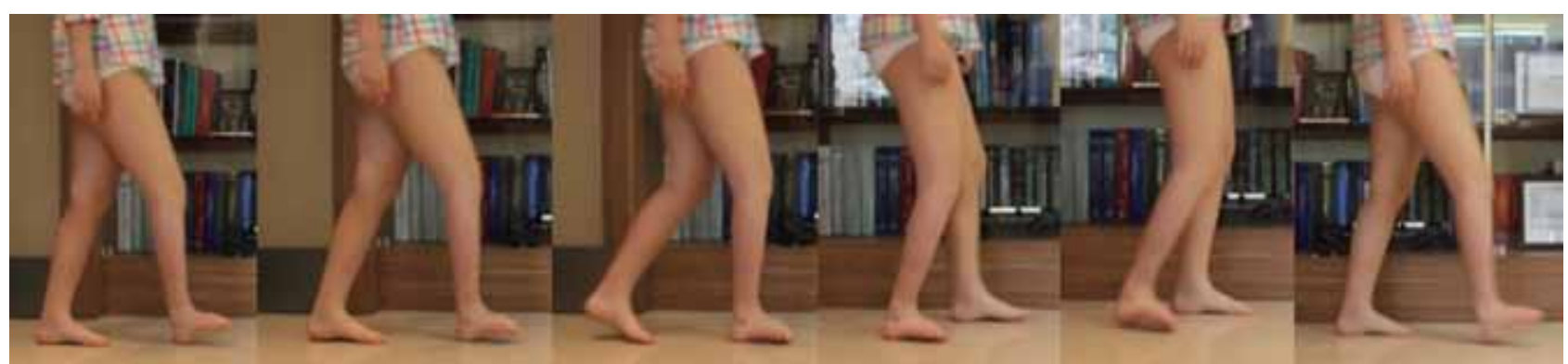

Şekil 3. Pes kalkaneus deformitesinde topuk teması fazında dorsifleksiyonun arttığı görülüyor.

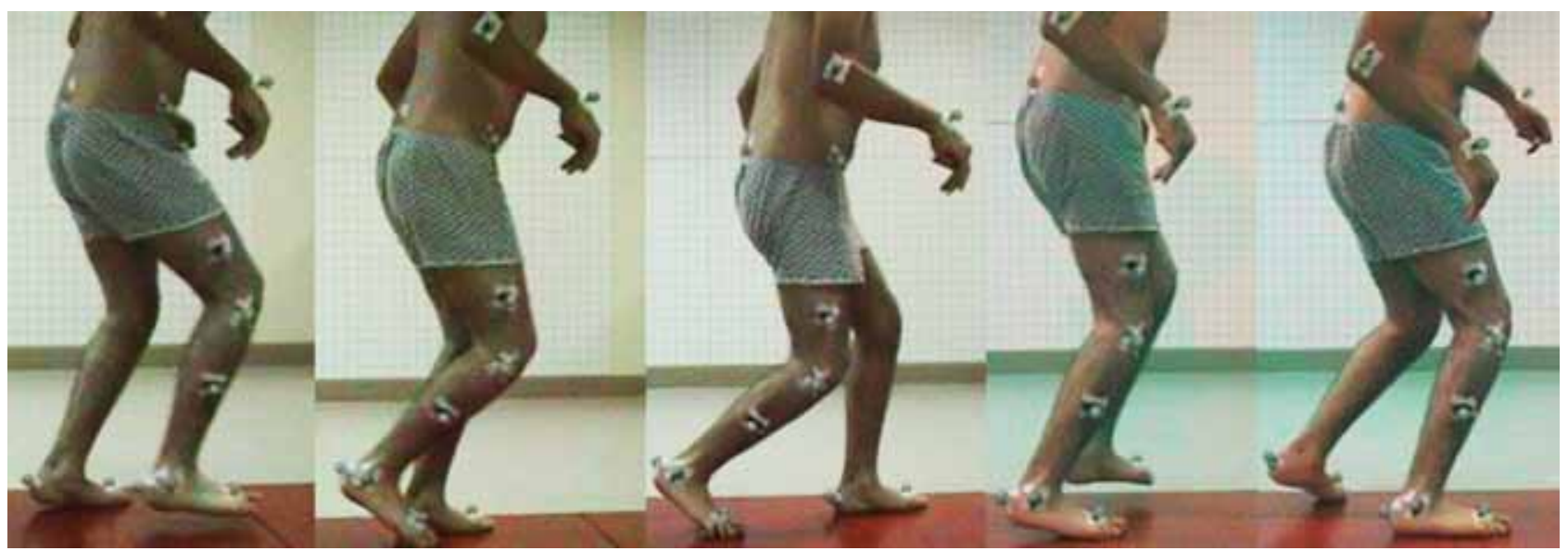

Şekil 4. Görsel yürüme analizinde basma fazında diz ekstansiyonunun yetersiz olduğu diz bükük yürüyüş görülüyor. 


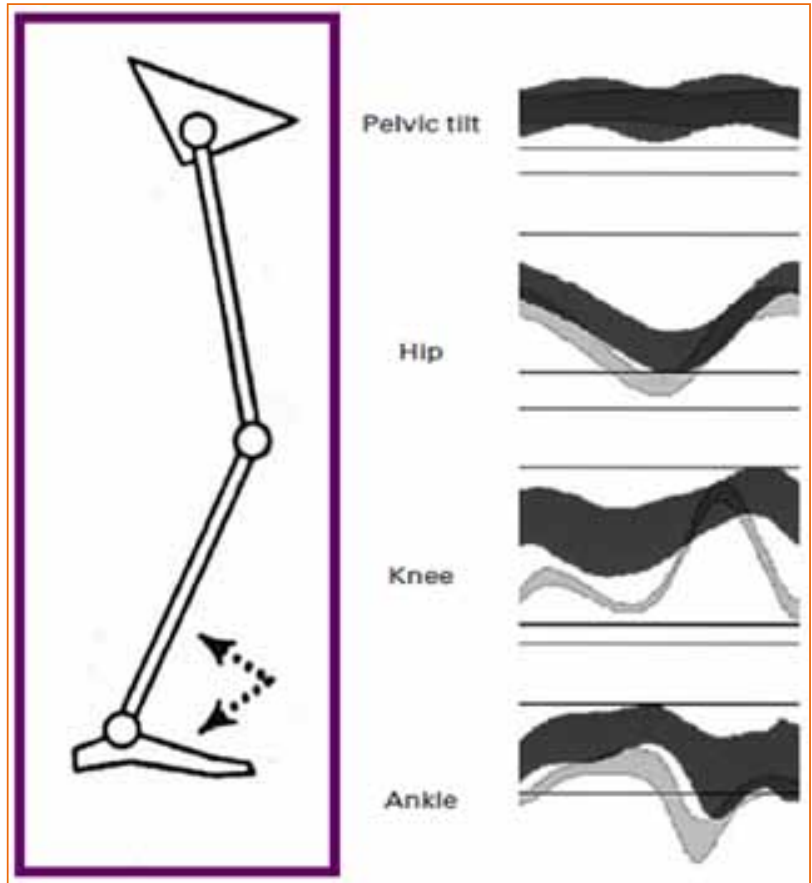

Şekil 5. Şematik çizimde ve yürüme analizi incelemesinde diz bükük yürüyüşe eşlik eden artmış kalça fleksiyonu ve ayak bileği dorsifleksiyonu görülüyor.

ekstansiyonu artması olarak tanımlanabilir. Bu değişimlerin sonucu olarak pelvik anterior tiltte ve lomber lordozda da artış gözlenir.

Sıçrayarak yürüme ayırıcı tanıda diz bükük yürüme ile karışabilmektedir. Bu noktada ayak bileğinin pozisyonu belirleyici olmaktadır: Artmış ayak bileği plantar fleksiyonu ile beraber artmış diz fleksiyonunun görülmesi sıçrayarak yürüme tanısını desteklerken, artmış ayak bileği dorsifleksiyonu bizi diz bükük yürüme tanısına yaklaştırır (Şekil 6).

\section{Sert diz yürüyüşü}

Yürüme sırasında dizin yeterli fleksiyona gelememesi sert diz yürüyüşü olarak tanımlanır. Kuadriseps artmış spastisitesi, ayak bileği artmış plantar fleksiyonu, kalça fleksör kas güçsüzlüğü sert diz yürüyüşüne neden olan patolojiler arasında sayılmaktadır (Şekil 7, 8).

Yetersiz diz fleksiyonu şok emiliminin aksamasına neden olur. Basma aşamasının sonunda gerçekleşmesi gereken parmak kalkışı güçleşir. Basma aşamasından salınım aşamasına geçiş güç ve karmaşık bir hal alır. Bu durumu dengelemek için kalça fleksiyonu artar. Ayak bileği cevap olarak dorsifleksiyona zorlanır, topuk temas süresi uzar ve sonuç olarak ayak bileğinde basma aşamasında üretilen enerji azalır. Salınım aşamasında

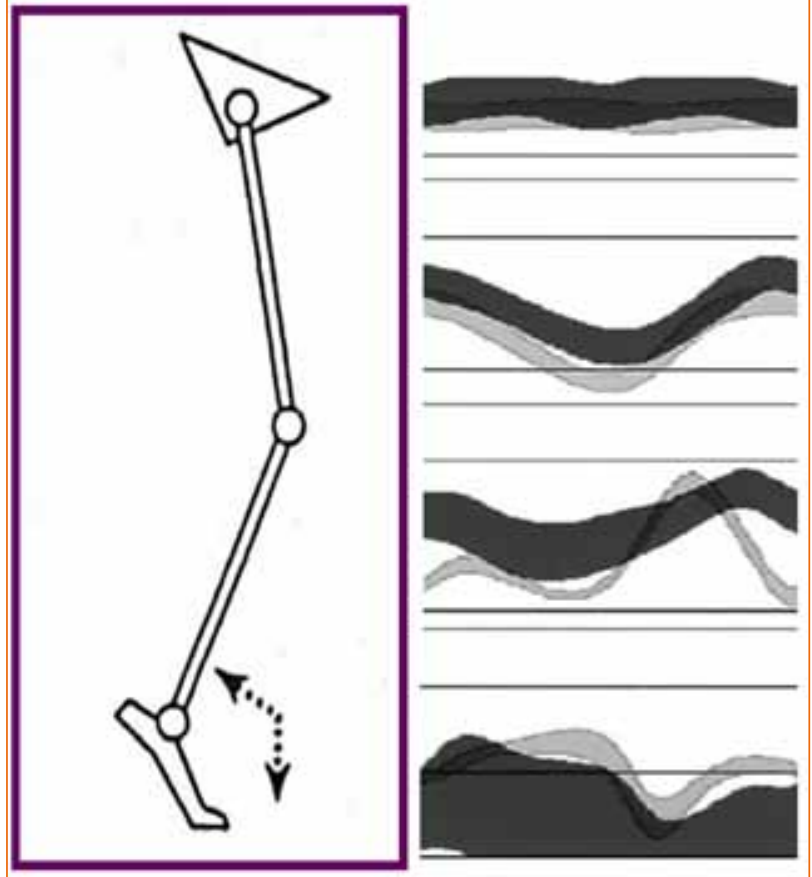

Şekil 6. Şematik çizimde ve yürüme analizi incelemesinde sıçrayarak yürüyüşe eşlik eden artmış kalça fleksiyonu ve ayak bileği plantar fleksiyonu görülüyor.

diz ekleminde yeterli fleksiyonun sağlanamaması parmak ucunun yer ile temasının devam etmesine yol açar. Bu durumda adım uzunluğu kısalır, yürüme hızı düşer, ekstremite boyunda bu aşamada gerçekleşmesi beklenen kısalma yetersiz kalır ve gövdenin öne ilerletilmesi güçleşir. ${ }^{[20]}$

Sert diz yürüyüşün tanısı erken salınım ve salınım ortası aşamalarında artmış rektus aktivitesinin elektromiyografi (EMG) ile tespiti, salınım aşamasında $55^{\circ}$ 'den az diz fleksiyonunun gözlenmesi, maksimum diz fleksiyonunun gecikmesi, yürüme hızının $75 \mathrm{~cm} / \mathrm{s}$ 'nin altına inmesi ve parmak ucunun yere sürtünmesi gibi klinik yakınmaların varlığı ile konur.

\section{Kalça patolojilerinin yürüme döngüsüne etkileri}

Kalça eklemi alt ekstremite ile gövde arasında köprü vazifesi üstlenmiştir ve alt ekstremitenin gövdenin altında ilerlemesini sağlar. Kalça ekleminden köken alan patolojiler gövde, pelvis, ve alt ekstremiteyi etkiler. Yürüme döngüsünün basma aşamasında kalça fleksiyondan ekstansiyona gelirken gövde öne doğru hareket eder. Salınım aşamasında ise tekrar fleksiyona gelir ve yer ile temasını kaybetmiş olan ekstremite öne doğru ilerler. Kalça eklemini ilgilendiren patolojiler genellikle sagittal planda (fleksiyon ve ekstansiyon) 


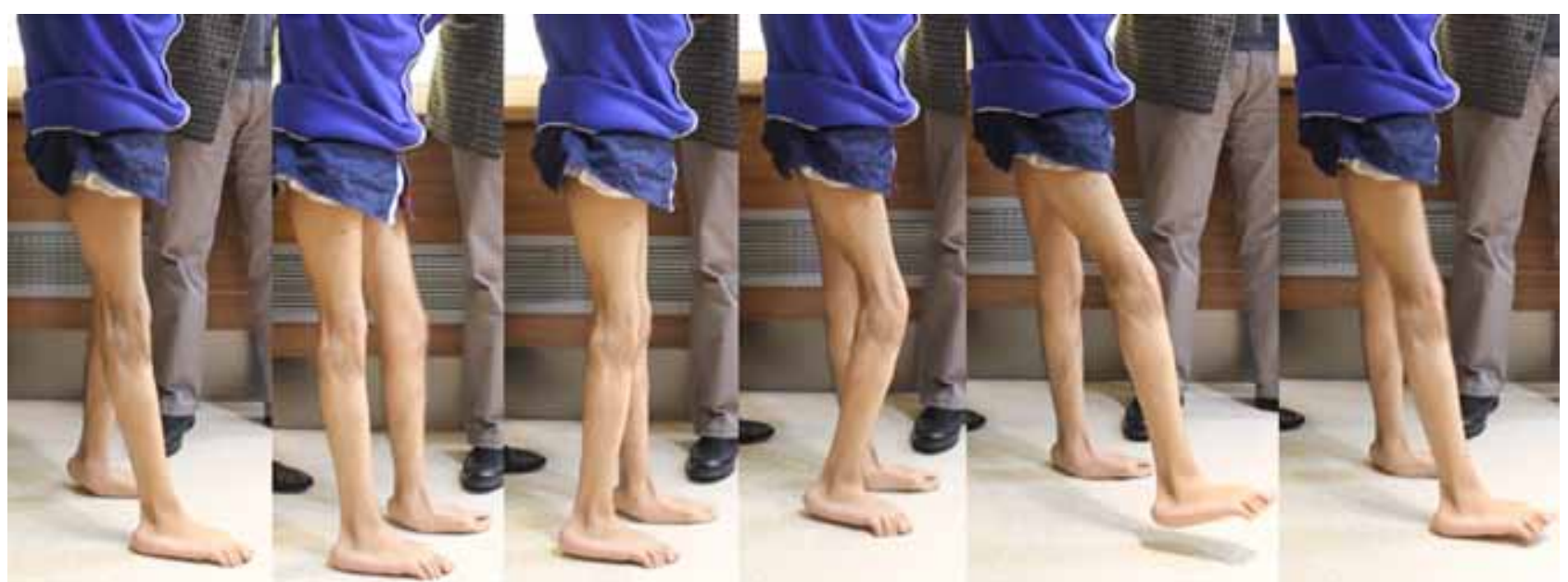

Şekil 7. Görsel yürüme analizi ile sert diz yürüyüşünün incelenmesi; salınım aşamasında yeterli diz fleksiyonu sağlanamıyor ve parmak ucunun yer ile temas süresi uzuyor.

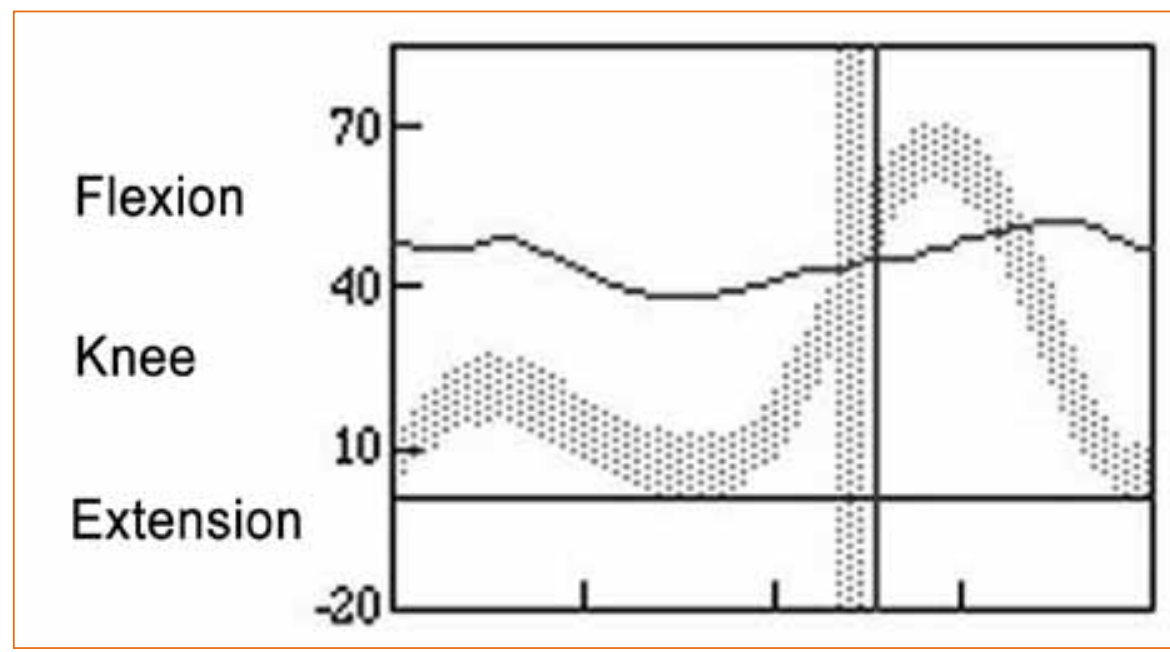

Şekil 8. Yürüme analizi ile incelenmesinde salınım fazında yeterli fleksiyonun sağlanamadığı sert diz yürüyüş görülüyor.

gerçekleşmekteyken diğer planlarda adduksiyon, abduksiyon ve rotasyonel (internal ve eksternal rotasyon) deformiteler karşımıza çıkabilir.

\section{Kalça fleksiyon yürüyüşü}

Kalça eklemini ilgilendiren ağrılı durumlar, eklem artrodezi, kalça fleksiyon kontraktürü, artmış kalça fleksör spastisitesi ve kalça ekstansör kas zaafiyeti kalça fleksiyonunda artma ile karakterizedir. Kalça eklemi artmış fleksiyonu, basma aşamasında stabilitenin sağlanmasını ve vücudun öne ilerlemesini güçleştirir.

Yürümenin tüm aşamalarında kalça ekleminin fleksiyonda kalması gövdeyi öne eğer, lomber lordozu arttırır ve dizi fleksiyona zorlar. Bunların sonucu olarak kuadriseps mekanizmasına binen yük artar ve ayak bileği dorsifleksiyona zorlanır.

\section{Kalça eklemi artmış adduksiyonu (makaslama yürüyüş)}

Kalça abduktor kas güçsüzlüğü, adduktor artmış spastisitesi ya da kontraktürü ve karşı taraf kalça eklemi abduksiyon kontraktürü sonucu kalça ekleminde artmış adduksiyon görülür. Bu gibi durumlarda ekstremitenin öne doğru ilerlemesi güçleşir. Tüm ekstremite mediyale kayar ve eğer etkilenen ekstremite karşı ekstremitenin önüne geçerse "makaslama" yürüyüşü gözlenir (Şekil 9).

Sonuç olarak, eklem patolojilerinin bilinmesi ve ayrıntılı olarak incelenmesi başarılı tedavinin değişmez şartıdır. Bu amaçla yürümenin gerek görsel gerekse üç boyutlu olarak analizi hekime önemli katkı sağlayacaktır. 


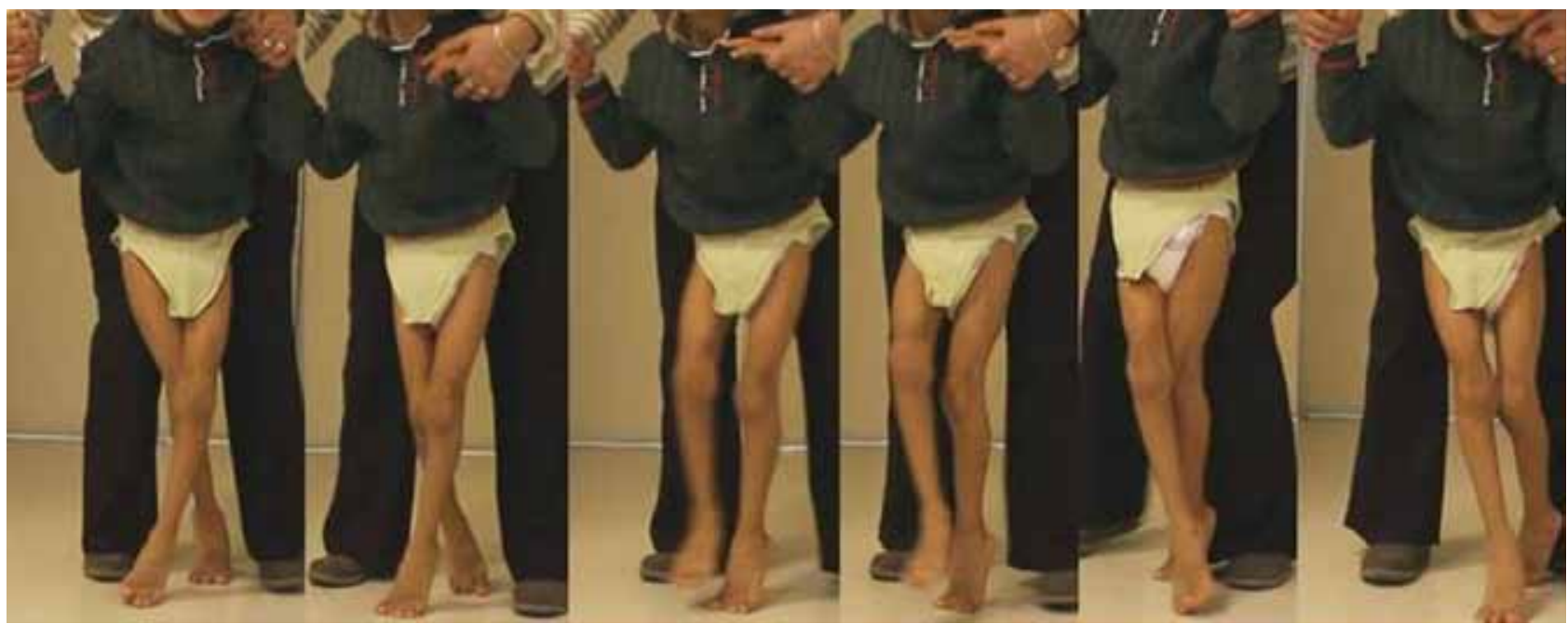

Şekil 9. Görsel yürüme analizi ile makaslama yürüyüşün incelenmesi; etkilenen ekstremitenin karşı ekstremitenin önüne geçtiği görülüyor.

\section{KAYNAKLAR}

1. Zajac FE, Neptune RR, Kautz SA. Biomechanics and muscle coordination of human walking: part II: lessons from dynamical simulations and clinical implications. Gait Posture 2003;17(1):1-17.

2. Zajac FE, Neptune RR, Kautz SA. Biomechanics and muscle coordination of human walking. Part I. introduction to concepts, power transfer, dynamics and simulations. Gait Posture 2002;16(3):215-32.

3. Gage JR. Surgical treatment of knee dysfunction in cerebral palsy. Clin Orthop Relat Res 1990;(253):45-54.

4. Martínez F, Cifuentes C, Romero E. Simulation of normal and pathological gaits using a fusion knowledge strategy. J Neuroeng Rehabil 2013;10:73. CrossRef

5. Torburn L, Perry J, Ayyappa E, Shanfield SL. Below-knee amputee gait with dynamic elastic response prosthetic feet: a pilot study. J Rehabil Res Dev 1990;27(4):369-84.

6. Tsintzas D, Ghosh S, Maffulli N, King JB, Padhiar N. The effect of ankle position on intracompartmental pressures of the leg. Acta Orthop Traumatol Turc 2009;43(1):42-8. CrossRef

7. Abrahamson MA, Skinner HB, Effeney DJ, Wilson LA. Prescription options for the below knee amputee. A review. Orthopedics 1985;8(2):210-20.

8. Waters RL, Perry J, Antonelli D, Hislop H. Energy cost of walking of amputees: the influence of level of amputation. J Bone Joint Surg Am 1976;58(1):42-6.

9. Perry J, Ireland ML, Gronley J, Hoffer MM. Predictive value of manual muscle testing and gait analysis in normal ankles by dynamic electromyography. Foot Ankle 1986;6(5):254-9.

10. Moraux A, Canal A, Ollivier G, Ledoux I, Doppler V, Payan C, Hogrel JY. Ankle dorsi- and plantar-flexion torques measured by dynamometry in healthy subjects from 5 to 80 years. BMC Musculoskelet Disord. 2013;14:104. CrossRef
11. Williams JR, Fitzhenry D, Grant L, Martyn D, Kerr DA. Diagnosis pathway for patients with amyotrophic lateral sclerosis: retrospective analysis of the US Medicare longitudinal claims database. BMC Neurol 2013;13:160. CrossRef

12. Perry J. Determinants of muscle function in the spastic lower extremity. Clin Orthop Relat Res 1993;(288):10-26.

13. Izzo KL, Aravabhumi S. Cerebrovascular accidents. Clin Podiatr Med Surg 1989;6(4):745-59.

14. Geuze RH. Postural control in children with developmental coordination disorder. Neural Plast 2005;12(2-3):183-96; discussion 263-72.

15. Demain A, Westby GW, Fernandez-Vidal S, Karachi C, Bonneville F, Do MC, Delmaire C, Dormont D, Bardinet E, Agid Y, Chastan N, Welter ML. High-level gait and balance disorders in the elderly: a midbrain disease? J Neurol 2014;261(1):196-206. CrossRef

16. Arnold AS, Lee DV, Biewener AA. Modulation of joint moments and work in the goat hindlimb with locomotor speed and surface grade. J Exp Biol 2013;216(Pt 12):220112. CrossRef

17. Kinney CL, Jaweed MM, Herbison GJ, Ditunno JF. Overwork effect on partially denervated rat soleus muscle. Arch Phys Med Rehabil 1986;67(5):286-9.

18. Perry J. Gait Analysis: Normal and pathologic function. Thorofare, NJ. SLACK Incorporated; 1992.

19. Hoang $H X$, Reinbolt JA. Crouched posture maximizes ground reaction forces generated by muscles. Gait Posture 2012;36(3):405-8. CrossRef

20. van der Krogt MM, Bregman DJ, Wisse M, Doorenbosch CA, Harlaar J, Collins SH. How crouch gait can dynamically induce stiff-knee gait. Ann Biomed Eng 2010;38(4):1593606. CrossRef 